\title{
Introduction to "Discrimination against Latin American Workers during Pre-Olympic Games Construction in Vancouver"
}

\author{
Victor G. Devinatz
}

Published online: 23 December 2010

(C) Springer Science+Business Media, LLC 2010

According to the International Labour Organization, globalization has led, in the last several decades of the twentieth century and the first decade of the twenty-first century, to a dramatic increase in migration as people leave their home countries in search of work in foreign countries. As of 2008, the United Nations (UN) estimates that there are approximately 214 million migrants throughout the world. Furthermore, the UN states that the United States and Canada have received migrants from all corners of the globe with many of these immigrants arriving from Latin America and the Caribbean although an increasing number are coming from Europe as well. As of 2010, the UN calculates that there are roughly 7.2 million migrants living in Canada.

In this well-written, informative and timely essay, Dr. Jeffrey Shantz, who currently teaches courses in human rights, community advocacy, corporate crime and social justice at Kwantlen Polytechnic University in British Columbia, Canada, analyzes a recent decision issued by the British Columbia Human Rights Tribunal concerning the discrimination experienced by Latin American workers who were employed on the building of the Canada Line rapid transit link for the nation's hosting of the 2010 Vancouver-Whistler Winter Olympics. In comparison to the Canadian and European workers laboring on the project, the tribunal ruled that the Latino workers were treated adversely. While Dr. Shantz also discusses in this essay the difficulties that labor unions undergo in protecting their members, the author argues that this decision is momentous in the global defense of labor rights.

I welcome employment relations scholars from around the globe to contribute future essays analyzing any employment-related topic from a wide variety of theoretical perspectives. Moreover, if any of the journal's readers would like to respond to particular essays published in the "Perspectives" Section, please do not hesitate to contact me with your proposal. I welcome both practitioner-based and scholarly-based articles. I hope that you enjoy this essay and find it most illuminating.

\footnotetext{
V. G. Devinatz ( $\square)$

Department of Management \& Quantitative Methods, Illinois State University, Normal, IL 61790-5580, USA

e-mail:vgdevin@ilstu.edu
} 